\title{
Performance Evaluation of Hydrodynamic Journal Bearing using Gearbox and Engine Oil (SAE90 and SAE20w50) by Experimental and Theoretical Methods
}

DOI: http://dx.doi.org/10.18535/ijmeit/v3i11.04

\author{
Srinivas ${ }^{1}$, Dr. Mohammed Yunus ${ }^{2}$, Duthors ${ }^{\text {Audi M. Muns hi }}{ }^{3}$, Iftekar Hussain H. ${ }^{4}$
}

1 Deparţment of Mechanical Engineering, SJC Institute of Technology, Chikaballapur, Karnataka, India

, 3 Department of Mechanical Engineering, Umm Al-Qura University, Makkah, Saudi Arabia.

Department of Mechanical Engineering, R and D centre, Bangalore, Karnataka, India

\begin{abstract}
A journal bearing consist of a shaft (or journal) which rotates freely in a supporting metal sleeve or shell and has no rolling elements. Shell type journal bearings support radial loading only, therefore construction and design is simple whereas understanding of theory and operation may be complex. Its extensive applications are in the field of turbo machinery components such as pumps, compressors and gas turbines as well as in automobile suspension system (transmission and suspension system). The performance of journal bearing depends on pressure distribution, load carrying capacity, frictional force, and speed, viscosity of oil etc. In this paper, an attempt has been made to present two different commercial lubricant oils such as SAE20W50 and SAE90 and their role in determining condition of lubrication (hydrodynamic or hydrostatic), type of pressure distribution and the stresses developed in the bearing under varying loads and speeds. The maximum pressure and Change of viscosity (before and after test) were determined and compared. The maximum stress developed at maximum pressure was $10.36 \mathrm{MPa}$. It is also noticed that, there is an increase in pressure from 0 to $80^{\circ}$ and then decreases to minimum for remaining rotation of bearing. This clearly indicates the presence of hydrodynamic lubrication in the journal bearing and good to use at higher speeds. It has been found that SAE90 bears more load than SAE20W50. Viscosity change shows that temperature has no or little effect. Results prove that an alternate and cheaper lubricant SAE graded oils can be used for improving performance of journal bearing.

Keywords-Hydrodynamic bearing, Viscosity, Pressure distribution, SAE graded oils, Sommerfield number, Lubrication.
\end{abstract}

\section{INTRODUCTION}

A journal bearing consist of a shaft (or journal) which rotates freely in a supporting metal sleeve or shell and has no rolling elements. Shell type journal bearings support radial loading only, therefore construction and design is simple whereas understanding of theory and operation may be complex. Oils are used in journal bearings when cooling is required or contaminants or debris need to be flushed away from the bearing. High-speed journal bearings are always lubricated with oil rather than grease. The viscosity grade required is dependent upon bearing RPM, oil temperature and load. Journal bearing finds an extensive application in the field of turbo machinery components such as pumps, compressors and gas turbines. It also finds application in automobile system such as transmission and suspension system. Journal bearing consists of the following parts as shown in Figure 1.

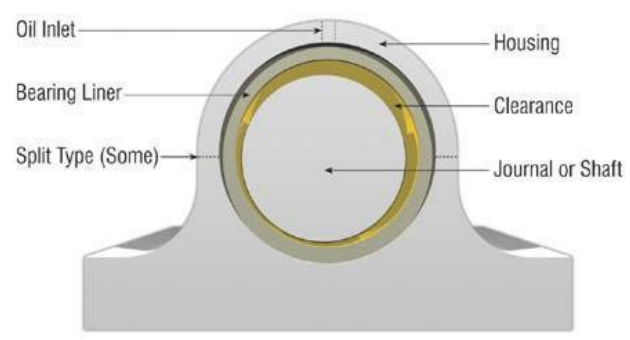

Fig. 1Different components of journal bearing 


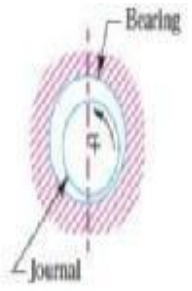

(a) Full journa baring

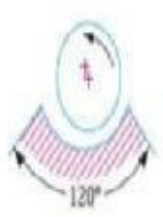

b) Fartal jounal beating,

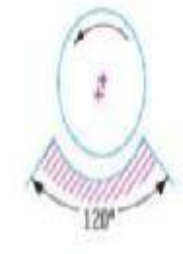

(c) Fitted jounal bearing,
Fig. 2 Types of journal bearing based on angle of contact

Based on angle of contact journal bearings are classified into full journal bearing, partial journal bearing and fitted journal bearing (refer figure 2).

\section{Introduction to Pressure Testing Equipment}

Figure 3 shows the journal bearing used to measure the pressure distribution of $180^{\circ}$ partial journal bearing. The equipment consists of a loading pan, oil reservoir, funnel shaped oil storage for supply of oil during testing, loading pan weights from $150 \mathrm{~N}$ to $750 \mathrm{~N}$, a bearing and a journal. It also consists of an oil regulator for supplying the oil during testing. The bearing is made out of Brass 60 whereas the shaft and other parts are made of EN31 steel.

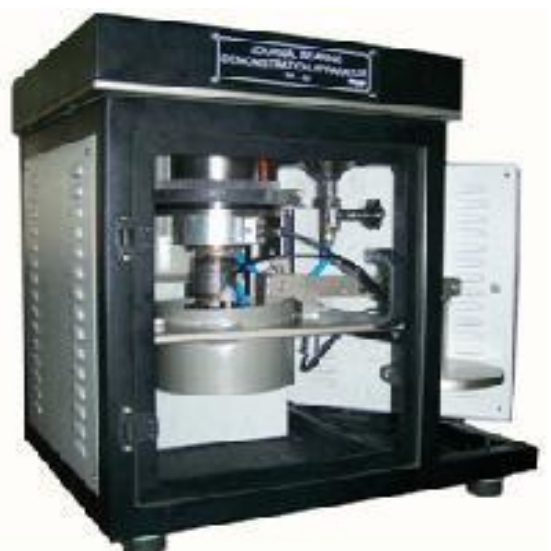

Fig. 3 Journal bearing test rig

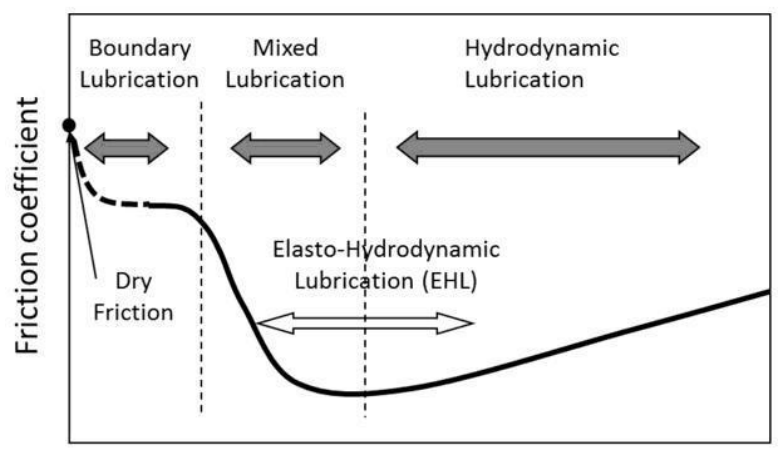

Lubrication parameter, $\mathrm{nV} / \mathrm{P}$

Fig. 4 Regimes of lubrication
There is indicator display board which is connected to the main instrument to get the readings of pressure and torque. The software Winducom is interfaced with the system to plot the graph of pressure distribution v/s angle (degrees) of the bearing. Similar trials can be carried out and all the readings such as maximum pressure and maximum angle are stored in the computer's hard drive. We can compare two or more results of the pressure distribution of the bearing with the aid of the software.

\subsection{Introduction to Regimes of Lubrication}

Fig 1.4 shows a stribeck curve which indicates the variation of friction co efficient v/s lubrication parameter. The $\mathrm{x}$ - axis is a function of two fluid parameters viscosity and speed of fluid, whereas $y$ axis shows the value of friction coefficient for different kinds of fluids for different speeds and loads. Wecan see that as we go towards right side there is increase in speed and viscosity but there is decrease in load carrying capacity of the lubricant.

\subsubsection{Boundary Lubrication}

It is a thin layer of lubricating film formed between the bearing and the journal surface. At this stage of journal it is not capable of carrying the load and not able to perform the desired function.

\subsubsection{Elasto-Hydrody namic Lubrication}

It is the second stage of lubrication which lies between the boundary and hydrodynamic lubrication. The fluid film thickness formed is greater than the surface roughness parameter so there is a surface contact i.e. (high point contact) is formed between the two surfaces. In mixed lubrication the surface asperities (meaning waviness on the surface) leads to non-formal contacts which in turn leads to elasto-hydrodynamic layer of lubrication.

\subsubsection{Hydrody namic lubrication}

This is a kind of lubrication where in there is continuous pressure development between bearing and journal surface due to continuous motion between the bearing and journal there is a constant film production. This is the kind of lubrication used 
in my work to study the pressure distribution of journal bearing. This kind of lubrication can be used to carry the loads.

\subsection{Objectives of Present Study}

1: To study the pressure distribution of SAE20W50 grade engine and SAE 90 grade gearbox oils (by varying the loads and varying speeds).

2: to determine the existence of hydrodynamic condition.

2: To calculate the load carrying capacity and frictional force of the journal bearing at maximum and minimum speeds

3: To determine the viscosity of oils after running for the given set of conditions to understand the effect of temperature.

4: To calculate the stress, strain and deformation by using analysis.

\section{REVIEW OF LITERATURE}

Experimental analysis of hydrodynamic journal bearing with different bio lubricants (Baskar and Sriram 2012) for pressure distribution of hydrodynamic bronze bearing and phosphorous journal bearing made with. The bearing is having a diameter of $45 \mathrm{~mm}$ and journal of diameter $40 \mathrm{~mm}$. The test was conducted at load values of $300 \mathrm{~N}$, $450 \mathrm{~N}$ and speed range of 1500rpm and 1750rpm. It has been observed that at clearance, either positive or negative pressure was developed without breaking bubble of the oil film in it and a continuous film was ensured. It is noticeable that there is a pressure variation of $10-20 \%$ in rapeseed oil as compared to SAE20W40 oil and small amount of variations in pressure distribution occurred when operated at loads of $300 \mathrm{~N}, 450 \mathrm{~N}$ and at a speed of $1500 \mathrm{rpm}$ and $1750 \mathrm{rpm}$. Whereas soya bean oil is used at similar conditions the pressure distribution was different with large variations as compared to rapeseed oil. Pressure(Ahar et. al.2013) analysis of plain journal bearing with lobe journal bearing and compared the results with plain journal bearing. The bearing has a dimension of $39.96 \mathrm{~mm}$ and bearing length of $40 \mathrm{~mm}$ clearance is around $0.185 \mathrm{~mm}$. Experiments were conducted at different loads such as $300,450,600,750 \mathrm{rpm}$ and at a varying speed of $1500 \mathrm{rpm}, 1000 \mathrm{rpm}$ and $2000 \mathrm{rpm}$ were conducted. The results said that there is a maximum pressure at a load of $750 \mathrm{~N}$ and speed of 2000rpm for a journal bearing whose value was1 151.2KPa and at the same conditions as a journal bearing the lobe bearing showed a value of $1192.6 \mathrm{KPa}$. The minimum pressure of journal bearing was found to be at $300 \mathrm{~N}$ and $1000 \mathrm{rpm}$ and that of journal bearing was $824.17 \mathrm{KPa}$. Thus for the same conditions one can conclude that for lower load conditions the increase was found to be by $30 \%$ and at higher load conditions it was $7 \%-10 \%$. The maximum value of pressure distribution of journal bearing was found to be $160^{\circ}-230^{\circ}$. Whereas the maximum value for lobe bearing was $165^{\circ}-225^{\circ}$. From this we can conclude that there is sudden rise in a short duration of time for a lobe journal bearing Hence stability of lobe bearing is more than that of journal bearing. Conducted various experiments and performing analytical calculations to obtain results of pressure distribution in journal bearing (Gulab and Dwarpalli, 2014). The following oils were used to test the performance.15w30, 20w40 and10w30 oils. In analytical method there were certain assumptions done and Reynolds equation was used to find the pressure. For experimental calculations JBTR instrument is used. Experiments were conducted for different trials i.e. at different speeds and different loads. When the test was conducted for $10 \mathrm{w} 30$ oil at $600 \mathrm{~N}$ load the result pressure obtained theoretically was $0.738 \mathrm{~N} / \mathrm{mm}^{2}$ and analytically was $0.662 \mathrm{~N} /$ $\mathrm{mm}^{2}$. The same test was conducted at $750 \mathrm{~N}$ the theoretical pressure was $1.37 \mathrm{Ns} /$ and the pressure found analytically was $1.28 \mathrm{~N} / \mathrm{mm}^{2}$.When the same test was conducted at $600 \mathrm{~N}$ the theoretical result was $1.131 \mathrm{~N} / \mathrm{mm}^{2}$ and analytical result was 1.117 $\mathrm{N} / \mathrm{mm}^{2}$. The theoretical results as compared with analytical results were found to be in good agreement. The fluid pressure increases from $0^{\circ}$ to certain angle and again reduces from the maximum value to $0^{\circ}$. This is the unique identity of hydrodynamic journal bearing. Conducted research on performance analysis of hydrodynamic and 
hydrostatic bearings they conducted analysis on a typical cylindrical journal bearing having the dimensions of journal diameter of $50 \mathrm{~mm}$ and bearing width of $25 \mathrm{~mm}$ and included angle of $30^{\circ}$ (Guo et al. 2005). They used the following software CFX-Tasc and VT-FAST to find the maximum pressure, load carrying capacity and attitude of the bearing for a normal mesh and a meshed bearing having a density of $148 \mathrm{~K}$ both the results were compared. Maximum pressure of VT FAST was found to be $2.328 \mathrm{X} \mathrm{Pa}$ and a load carrying capacity of $1151 \mathrm{~N}$ and an attitude of $49.4^{\circ}$. The same test was conducted on VT Express which is having a mesh density of $52 \mathrm{~K}$, it yielded a pressure value of $2.324 \mathrm{KPa}$ and a load carrying capacity of $1144 \mathrm{~N}$ and an attitude of $49.3^{\circ}$. The results as compared with $148 \mathrm{k}$ mesh were found to deviate by a nominal percentage of $0.99 \%$ by VT-FAST and $1.16 \%$ by VT-EXPRESS for load carrying capacity. The variation in load carrying capacity for VT-FAST was $0.43 \%$ and $1.14 \%$ for VT-EXPRESS. He also conducted thermal analysis on a four pocket hydrostatic journal bearing with bearing diameter of $30 \mathrm{~mm}$ and width of $20 \mathrm{~mm}$ and radial clearance of $0.03 \mathrm{~mm}$. The supply pressure is $5 \mathrm{MPa}$ for the same conditions he conducted experiments on hydrostatic and hybrid operated bearing. The following results were obtained for CFX-TASC analysis on hydrostatic bearing flow pocket inlet pressure is $2.657 \mathrm{MPa}$, Load carrying capacity is $722.7 \mathrm{~N}$ and flow rate is $0.0324 \mathrm{~kg}$-s. The results obtained by VTExpress software varied the CFX-TASC by a value of $0.3 \%$ for pressure and $13.2 \%$ for load carrying capacity. The same test conditions were done on hybrid operating journal bearing the following results were obtained by CFX-TASC flow process the inlet pressure was $2.671 \mathrm{Mpa}$, load carrying capacity was $727 \mathrm{~N}$ and flow rate was 0.0318 and an attitude of $23.4^{\circ}$.the results of VT express varied from CFX-TASC by a pressure value of $1.9 \%$ and load carrying capacity of $8.3 \%$ and by $4.6 \%$ for flow rate. From the above results we can conclude that the pressures of both hydrostatic and hydrodynamic bearings are very much close to the stand ard code, whereas the value of load carrying capacity increased slightly greater than the standard one due to reduction in inlet pressure in the direction opposite to the eccentricity direction. Investigation on pressure distribution and load carrying capacity of journal bearing using finite element and analytical method (Nuruzzaman et al. 2010). Certain assumptions (i.e. Reynolds assumption) are being made to solve the problem in analytical method. The Reynolds equation is solved using weighted residual method. The FEM method is solved by interpreting the system in the form of $\mathrm{KQ}=\mathrm{F}$ and by knowing the shape functions and order of the element Jacobian of the matrix can be obtained. By incorporating the Jacobian in the Reynolds equation and by using suitable formulae stiffness of the bearing is obtained. The experiments were conducted on a bearing which had an eccentricity of 0.4 and shaft speed of 5000rpm, , $=0.004$. It is seen that pressure increased steadily from zero to maximum and then reduced to zero. The maximum pressure was seen at $1.5 \mathrm{~N} /$ for analytical a $1.4 \mathrm{~N} /$ for journal running at $5000 \mathrm{rpm}$ and eccentricity of 0.4 . The maximum pressure was seen at $3 \mathrm{~N} /$ for analytical and $2.8 \mathrm{~N} /$ when the journal is rotating at $10000 \mathrm{rpm}$ and eccentricity of 0.4 . From the above two results we can conclude that experimental and fem results were very close to each other and in good agreement. Some discrepancy was found between analytical and fem results because in analytical solution half Sommerfield boundary for calculation. When the variation of load carrying capacity with eccentricity it was seen that load carrying capacity of bearing gradually increased with eccentricity of the bearing. It was also seen that load carrying capacity increased with increase in shaft speed. Comparison of fem results with analytical results showed similar variation and the results were in good agreement.

\section{MATERIAL AND METHODS}

\section{Types of Oils used}

SAE20W50: It is engine oil. The term w means that it is winter grade oil where 20 indicates viscosity at 
low temperature (viscosity at which the oil is passed into the engine for easy start) and 50 indicates viscosity at high temperature of oil.

SAE90 oil: It is gear box oil. These lubricants are used in gear boxes which are having very high temperature at the surface of two surfaces.

\section{Description of Bearing Test Rig -60}

Journal bearing test rig is an instrument used to measure the pressure distribution of the $180^{\circ}$ partial journal bearing. The test rig consists of a frame, a bearing unit, bearing unit and loading, drive, lubrication, control and measuring system. The frame is structurally rigid to avoid disturbing deformations and vibrations. The unit consists of a bearing, housing, shaft and supporting bearings. The housing in which bearing is placed is having a simplified circular design. There is a single pneumatic cylinder on which both static and dynamic load is given to the bearing. The drive system drives the shaft and consists of a power unit and transmission unit. Belt is used to for transmission for accurate rotational speed control, the power unit is driven by a variable frequency drive and voltage is connected to the motor to decrease variation in rotation speed. The lubrication system lubricates the bearing it consists of a tank with bearing immersed inside it, the control system controls the main operations of the test rig and automated control system have been favoured.

Table 1. Description of SAE90 grade oil

\begin{tabular}{|l|l|l|}
\hline No & SAE90 grade oil & Specification \\
\hline 1 & Density @ $15^{\circ} \mathrm{C}$ according to ASTM D1298 & $0.89 \mathrm{~g} / \mathrm{ml}$ \\
\hline 2 & Appearance & Bright \&clear \\
\hline 3 & $\begin{array}{l}\text { Kinemat ic Viscosity at } 100^{\circ} \mathrm{C} \text { according to } \\
\text { AST M D445 }\end{array}$ & 16.5 \\
\hline 4 & Viscosity Index according to ASTM D2270 & 95 \\
\hline 5 & Flash point according to ASTM D93 & $>180^{\circ} \mathrm{C}$ \\
\hline 6 & $\begin{array}{l}\text { Kinematic viscosity at } 40^{\circ} \mathrm{C} \text { according to } \\
\text { AST M D445 }\end{array}$ & 180 \\
\hline
\end{tabular}

Table 2. Description of SAE20W50 oil

\begin{tabular}{|l|l|l|}
\hline No. & SAE 20W50 oil & Specification \\
\hline 1 & $\begin{array}{l}\text { Kinematic viscosity at } 100^{\circ} \mathrm{C} \text { according to } \\
\text { ASTM D445 }\end{array}$ & 183 centistokes \\
\hline 2 & $\begin{array}{l}\text { Kinematic viscosity at } 40^{\circ} \mathrm{C} \text { according to ASTM } \\
\text { D445 }\end{array}$ & 171 centistokes \\
\hline 3 & Viscosity Index according to ASTM D2270 & 119 \\
\hline 4 & Pour point & $-30^{\circ} \mathrm{C}$ \\
\hline 5 & Sulphated ash in \% weight & 0.80 \\
\hline
\end{tabular}

\begin{tabular}{|l|l|}
\hline 6 & Zinc in \% weight \\
\hline
\end{tabular}

0.086

Table 3. Journal bearing description

\begin{tabular}{|l|l|l|}
\hline No. & Description & Specification \\
\hline 1 & $\begin{array}{l}\text { Joumal outer diameter and } \\
\text { material }\end{array}$ & $\begin{array}{l}\text { EN31 bearing steel, hardened to } 60 \mathrm{Hrc}, \text { ground } \\
\text { to1.6Ra surface roughnesss, } \varnothing 39.965\end{array}$ \\
\hline 2 & Test bearing size & $\begin{array}{l}\text { Material brass } 60-40 \% \text {, pressure tested innerdia. } \\
40.15\end{array}$ \\
\hline 3 & Radial clearance & $0.0925 \mathrm{~mm}$ \\
\hline 4 & Length/dia (LD) ratio & 1 \\
\hline 5 & r/c ratio & 216.2 \\
\hline
\end{tabular}

Table 4. Equipment description: Journal bearing test rig

\begin{tabular}{|l|l|l|}
\hline No. & Description & Specification \\
\hline 1 & Pulley ratio & $1: 1$ \\
\hline 2 & Base plate height from floor & $235 \mathrm{~mm}$ \\
\hline 3 & Journal height from base plate & $40 \mathrm{~mm}$ \\
\hline 4 & Loading bracket height from base plate & $65 \mathrm{~mm}$ \\
\hline 5 & Radial load & $150 \mathrm{~N}-750 \mathrm{~N}$ \\
\hline 6 & Oil tank cap & 3 litres \\
\hline 7 & Oil reservoir capacity & $500 \mathrm{ml}$ \\
\hline 8 & Dead weight on bearing & $35 \mathrm{~N}$ \\
\hline 9 & Loading ratio & $1: 5$ \\
\hline 10 & Torque dist ance for frictional force & $200-2000 \mathrm{rpm}$ \\
\hline 11 & Journal speed & $200-2000 \mathrm{rpm}$ \\
\hline 12 & Overall size of themachine LXWXH & $640 \times 520 \times 625 \mathrm{~mm}$ \\
\hline 13 & Weight of the machine & $110 \mathrm{~kg}$ \\
\hline 14 & Weight of the controller & $7 \mathrm{~kg}$ \\
\hline 15 & Floor size LXW & $(1500 \times 1500) \mathrm{mm}$ \\
\hline
\end{tabular}

Table 5. Bearing and Journal material descriptions

\begin{tabular}{|c|l|l|l|}
\hline No. & Material & Specification & Application \\
\hline 1 & & $\begin{array}{l}\text { Density:8.39- } \\
\text { Elastic modulus: } 110 \mathrm{GPa} \\
\text { Ultimate strength }: 370-485 \mathrm{MPa} \\
\text { Shear Strength:275-305 MPa }\end{array}$ & $\begin{array}{l}\text { Bearing } \\
\text { material }\end{array}$ \\
\hline \multirow{2}{*}{ Brass 60} & $\begin{array}{l}\text { Tensile strength: } 750 \mathrm{MPa} \\
\text { Yield stress: } 450 \mathrm{MPa} \\
\text { Modulus of elasticity:215000 MPa } \\
\text { Steel }\end{array}$ & $\begin{array}{l}\text { Lensity: } 8 \text { - } \\
\text { Hardness:60 HRc }\end{array}$ & and oil cup \\
\hline
\end{tabular}

The test is carried out by placing a suitable load on the pan and adjusting the speed according to the given loading conditions. The bearing is placed in the home position and the oil supply is switched on and the flow is ensured between journal and bearing surface. there is a pressure sensor to sense the pressure and load cell which indicates the load acting on the bearing and converts the load into strain by using strain gauge and this turn converts into resistivity of the circuit to indicate the strain by using wheat stone bridge circuit. There is a dwell position at every $9^{\circ}$ rotation of the bearing due to indexing mechanis $m$ attached to it. 


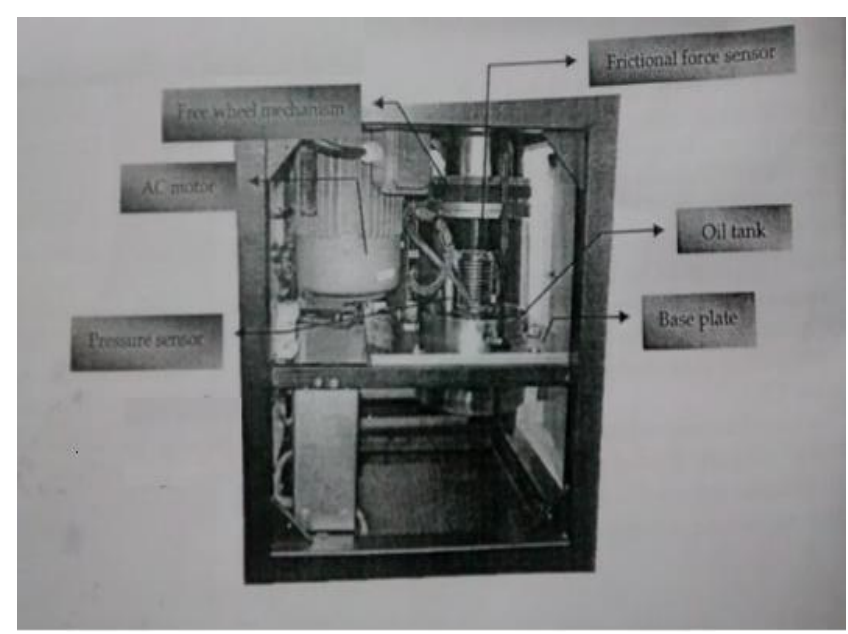

Fig. 5 Components of a journal bearing test rig

\section{Bearing Unit:}

It consists of a test bearing, oil tank, shaft (journal) supporting bearings (inside spindle housing) and a loading lever. The rotating shaft is vertically on bearings with negligible bearing play inside the spindle housing mounted on top plate, the journal is rotated by an AC motor with flat belt having 1:1pulley ratio to achieve 2000rpm. The test bearing is made of brass and aluminium machined with high accuracy with the inner and bearing ground to a roughness value of $\mathrm{Ra}=0.6$ by maintaining required dimensions as per drawing standards. The inner diameter of the bearing is $39.965 \mathrm{~mm}$ and diameter is $40.025 \mathrm{~mm}$ with bearing freely slides over shaft diameter with a $1 / d$ ratio of 1 . The bearing is freely suspended from the bottom of frictional force load cell by a metallic bellow so that restraining force due rotation of journal measured by load cell and measured as frictional force.

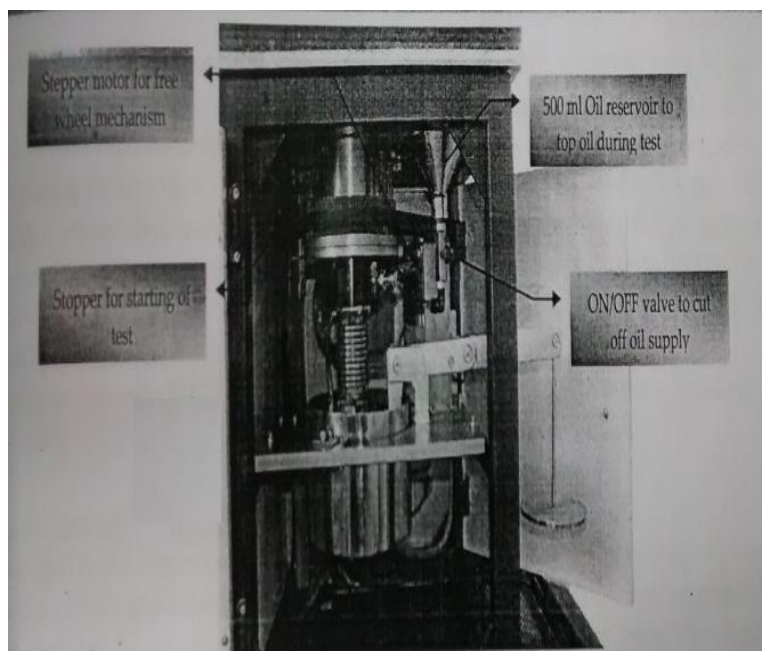

Fig. 6 Image of journal bearing test rig
To measure bearing pressure a pressure sensor is mounted on the face of bearing facing vertically upwards the sensor tip is immersed in oil. Radial load on the bearing is applied by a $\mathrm{L}$ shaped loading lever pivoted over the base plate with a lever ratio 1:5 ratio mechanical advantage to apply a maximum of $750 \mathrm{~N}$.The bearing is indexed along with the pressure sensor to measure frictional force at $9^{\circ}$ steps by a stepper motor driving a free wheel mechanism through belt. The free wheel mechanism is mounted above the frictional force sensor centralised by a ball bearing over journal so that the test bearing always runs towards the centre of bearing during indexing. To repeat the same position on bearing for each run before starting of test the bearing is pushed to a stopper and after completion of $180^{\circ}$ indexing position the bearing is manually pushed to the starting position against stopper. The hydrodynamic condition is created by the rotation of journal inside bearing immersed in oil inside as tank; the speed of rotation creates cavitations sucking oil between shafts and bearing surface. The oil level inside tank is maintained till the bearing top surface during testing by a $500 \mathrm{ml}$ oil reservoir mounted on top plate to eliminate oil starvation during the test.

\section{RESULTS AND DISCUSSIONS}

\subsection{Results of Pressure Distribution using SAE20w50 Oil at constant load but Varying Speed}

We notice a maximum pressure at $800 \mathrm{rpm}$ when the load is of either low or high whereas for medium load capacity, it occurs at higher speed of $900 \mathrm{rpm}$. This could be due to change of eccentric ity at higher loads but lower speeds or vice versa and heat generation which change the viscosity. Up to $50^{\circ}$ of rotation of the bearing, the variations of pressure remains to minimum value, then suddenly rises to a maximum value for next $25^{\circ}$ to $30^{\circ}$ of rotation and then pressure down to a minimum for next $25^{\circ}$ of rotation and remains constant till end of rotation. 


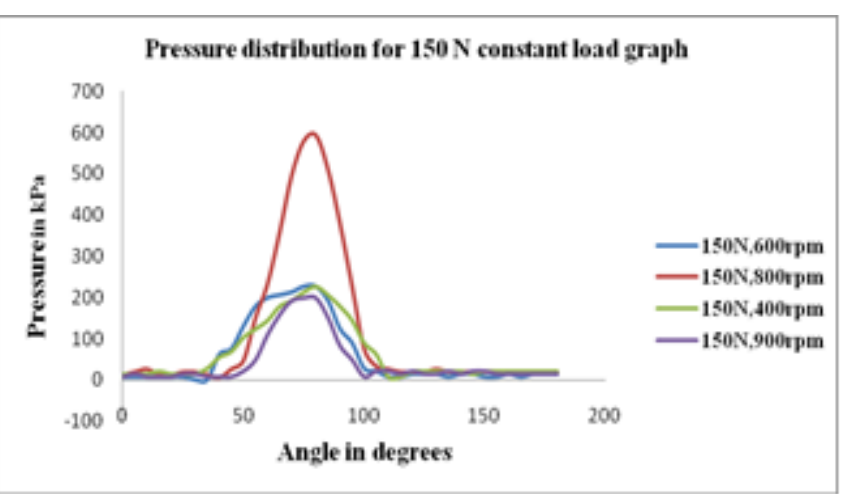

Fig. 7 Pressure distribution variation at constant load of $150 \mathrm{~N}$

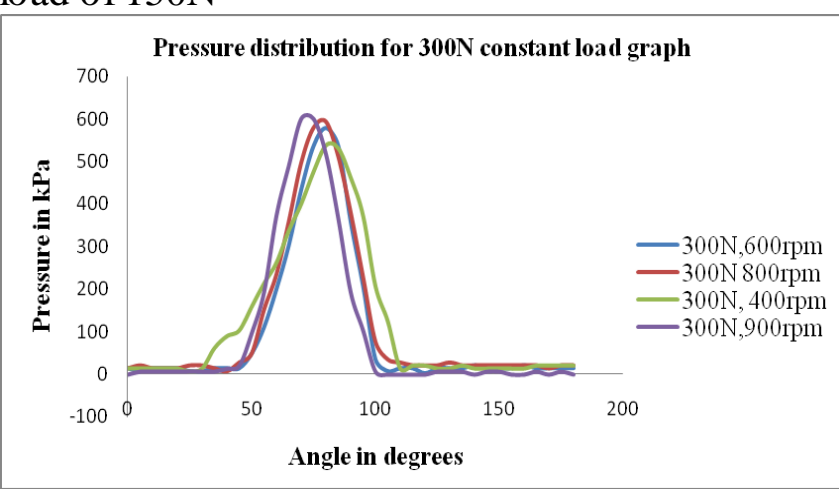

Fig. 8 Pressure distribution variation at constant load of $300 \mathrm{~N}$

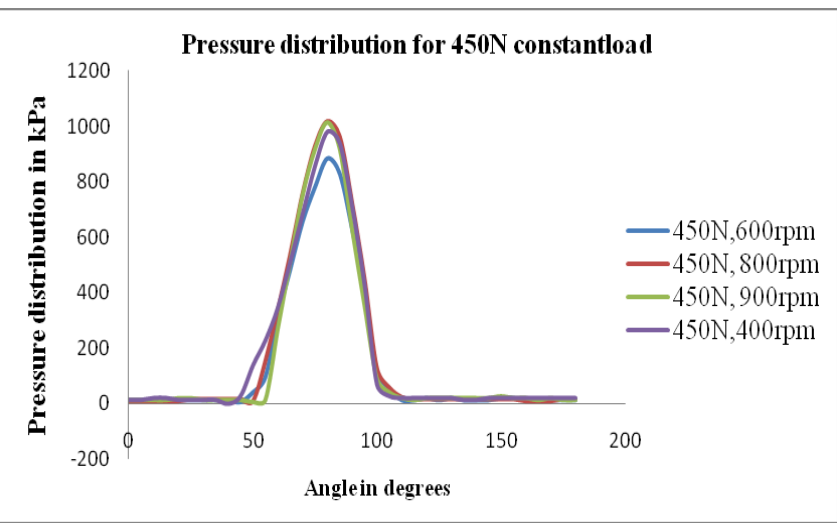

Fig. 9 Pressure distribution variation at constant load of $450 \mathrm{~N}$

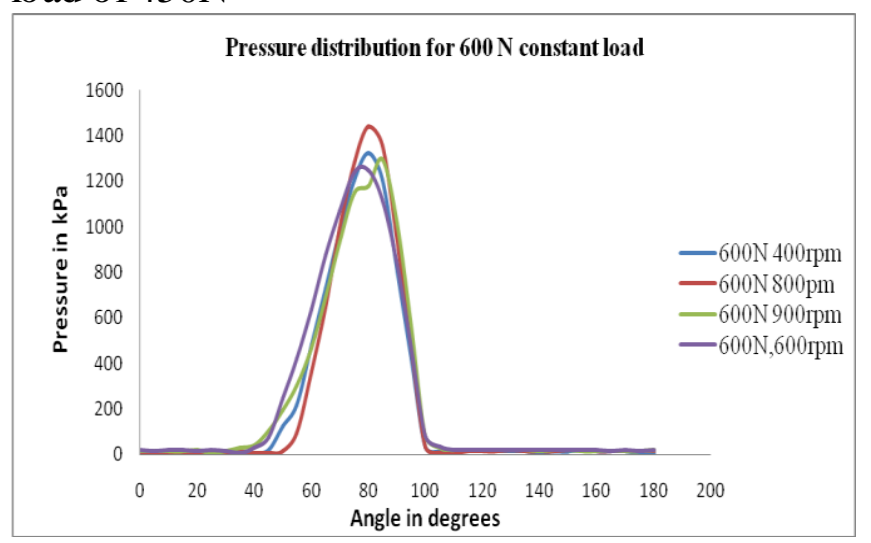

Fig. 10 Pressure distribution variation at constant load of $600 \mathrm{~N}$
Similarly, pressure distribution is found with the maximum pressure at higher load of $600 \mathrm{~N}$ in case of different speeds

\subsection{Results of Pressure Distribution using SAE20w50 Oil at constant speed but Varying Load}

Maximum pressure of $1324 \mathrm{KPa}$ is obtained for $600 \mathrm{~N}$ load at a speed of 400rpm and a minimum of $6.9 \mathrm{KPa}$ as shown in figure11.Up to 500 of rotation, the pressure variation remains minimal, then suddenly rises to a maximum value for next 250 to300 of rotation and then for next 250 of rotation of the bearing, it falls to a minimum pressure and remains constant till the end of rotation. Similar pressure distribution is found such as maximum pressure at different speeds but at higher load of $600 \mathrm{~N}$.

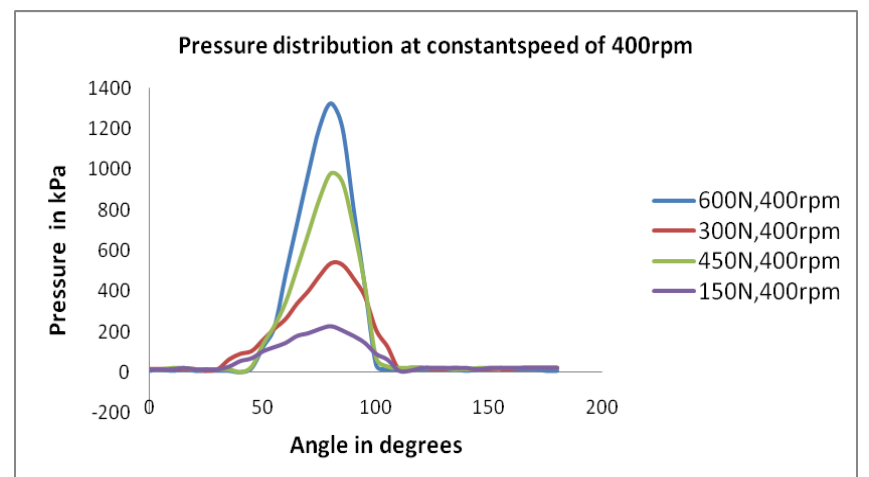

Fig. 11 Pressure distribution variation at a speed of 400rpm

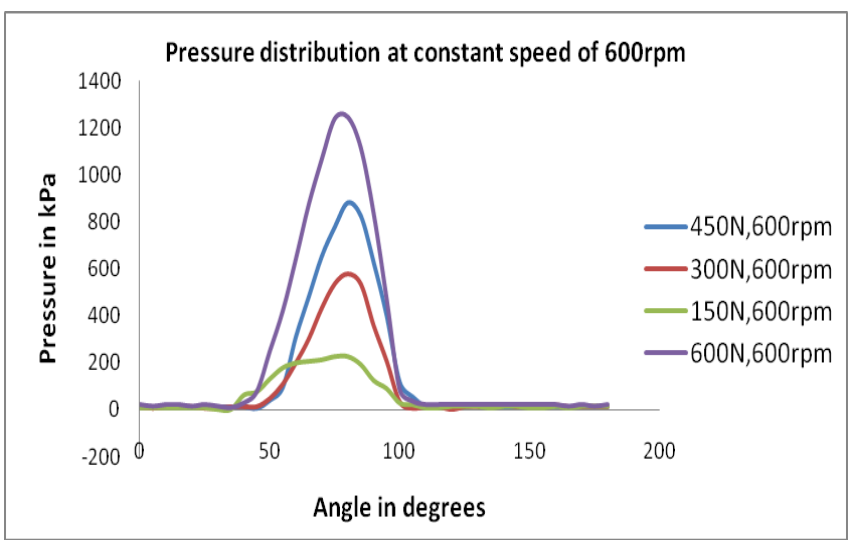

Fig. 12 Pressure distribution variation at a speed of $600 \mathrm{rpm}$ 


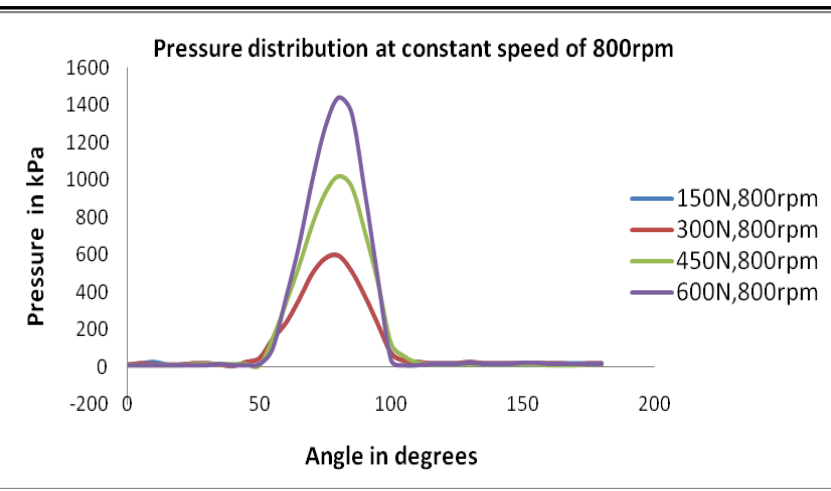

Fig. 13 Pressure distribution variation at a speed of $800 \mathrm{rpm}$

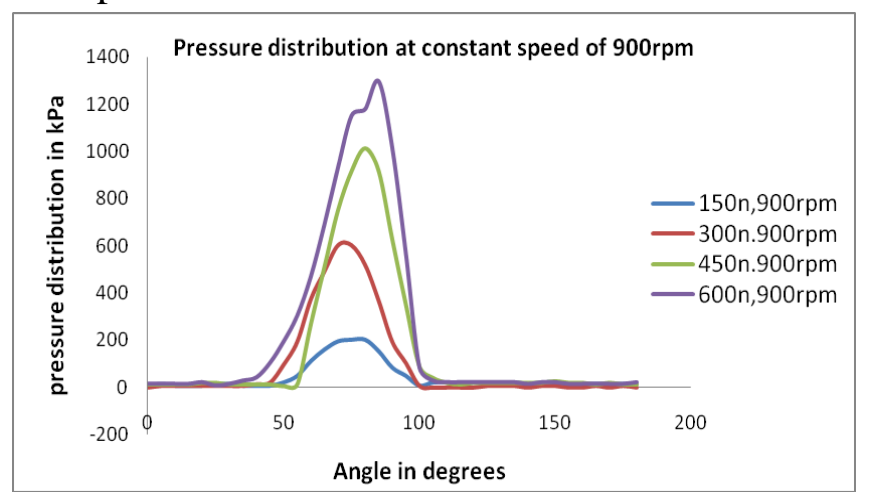

Fig. 14 Pressure distribution variation at a speed of $900 \mathrm{rpm}$

As noticed previously the variation in pressure here can also be accounted for the change in the eccentric position between the journal and bearing and viscosity change at higher speed and load.

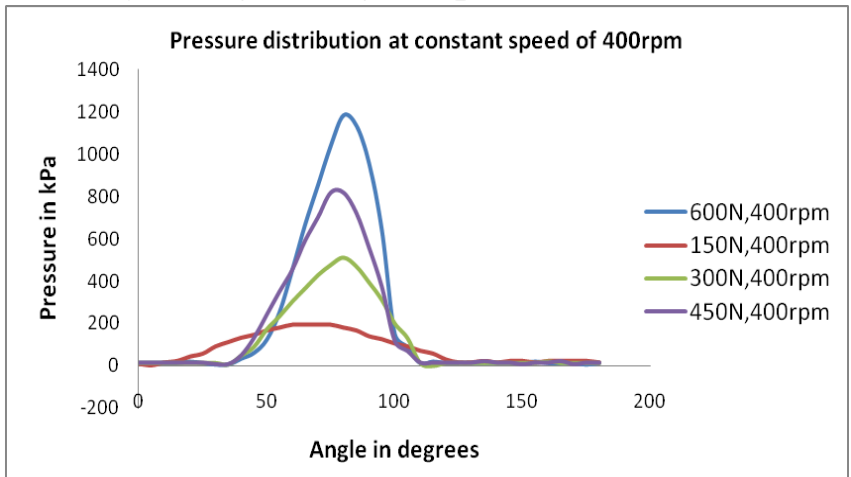

Fig. 15 Pressure distribution variation at a speed of 400rpm

\subsection{Results of Pressure Distribution using SAE90 Oil at Constant Speed but Varying Load}

We can observe that a maximum pressure of 1193 $\mathrm{KPa}$ is observed for the condition of $600 \mathrm{~N}$ and a minimum pressure of $6.9 \mathrm{KPa}$ is obtained.

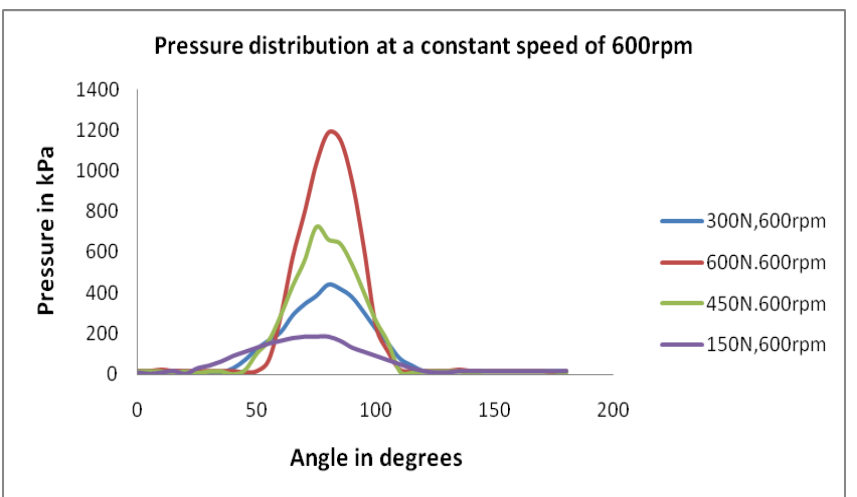

Fig. 16 Pressure dis tribution variation at a speed of $600 \mathrm{rpm}$

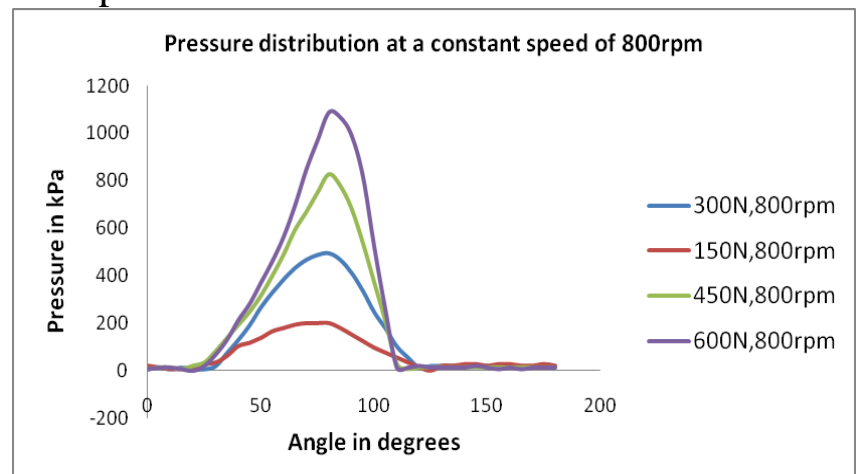

Fig. 17 Pressure distribution variation at a speed of $800 \mathrm{rpm}$

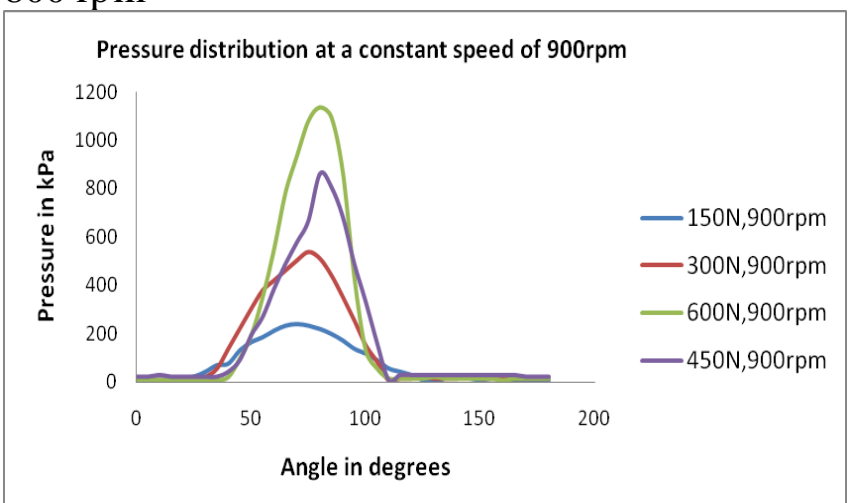

Fig. 18 Pressure distribution variation at a speed of $900 \mathrm{rpm}$

At lower intensity of loads we come across nonuniform pressure distribution due to the change in the eccentric position between the journal and bearing and decrease in viscosity.

\subsection{Results of Pressure Distribution using SAE90 Oil at Constant Load but Varying Speed}

Figures show the variation of pressure for different loading conditions by maintaining speed as a constant parameter. From Fig. 19, we can see that maximum 
is at $6.9 \mathrm{KPa}$. For nearly $12.5 \%$ of the graph the variation remains horizontal and then suddenly rises to a maximum value for another $25 \%$ of the graph and then falls down to minimum condition.

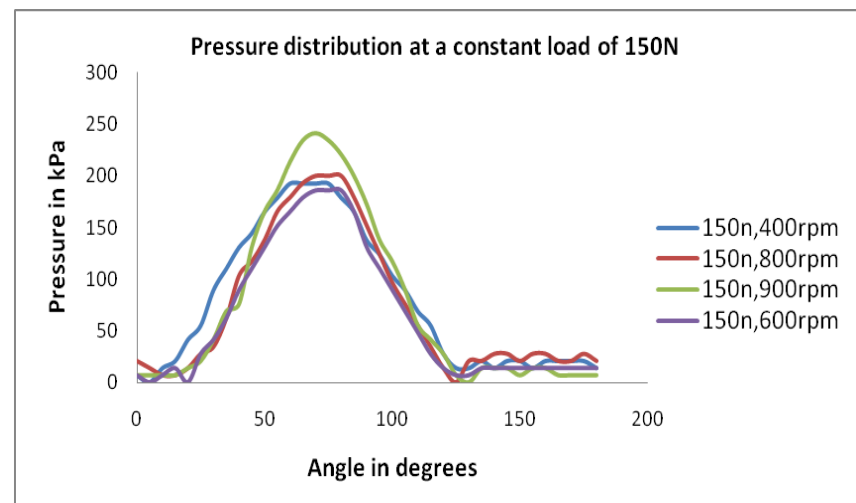

Fig. 19 Pressure distribution variation at constant load of150 N

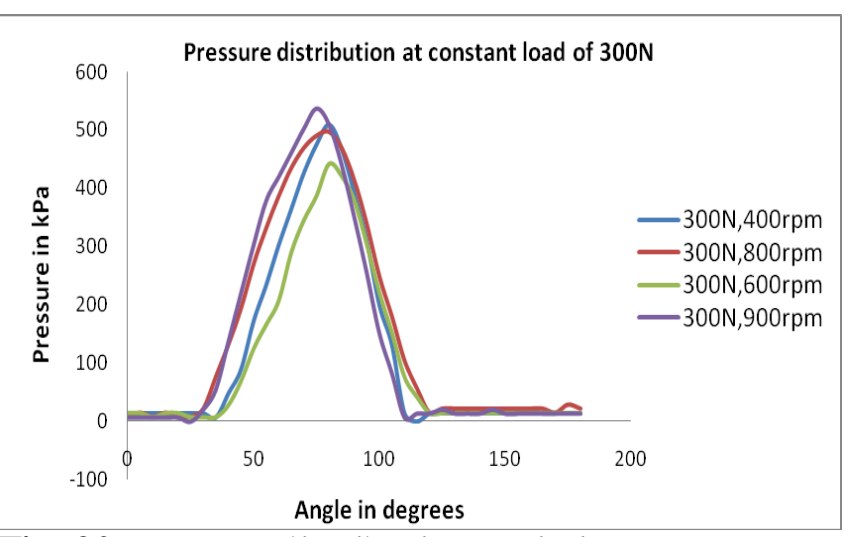

Fig. 20 Pressure distribution variation at constant load of $300 \mathrm{~N}$

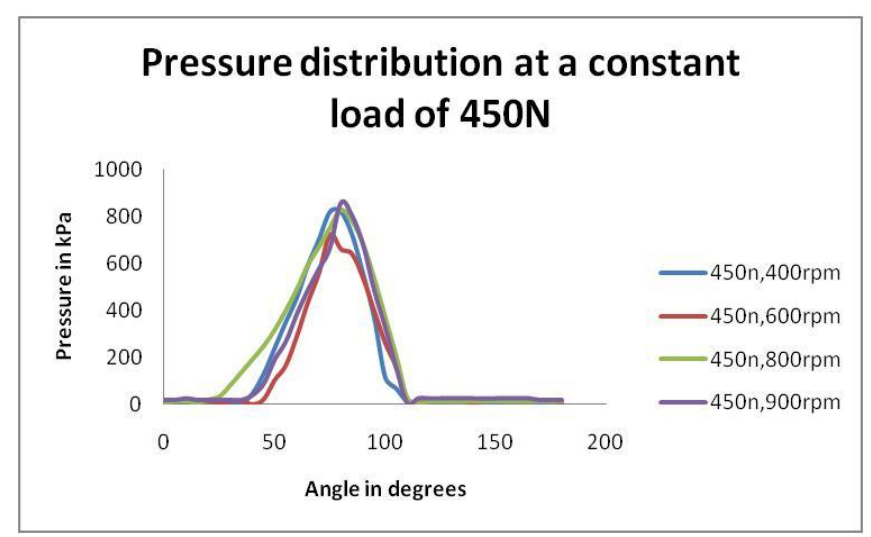

Fig. 21 Pressure distribution variation at constant load of $450 \mathrm{~N}$

From Fig. 20, we can make out that there is a maximum pressure of $538 \mathrm{KPa}$ for 300N, 900rpm and minimum pressure of $13.8 \mathrm{KPa}$. From Fig. 22, it is observed that there is a maximum and minimum pressure of $1200 \mathrm{KPa}$ and $6.9 \mathrm{KPa}$ respectively for $600 \mathrm{~N}$ at $600 \mathrm{rpm}$.

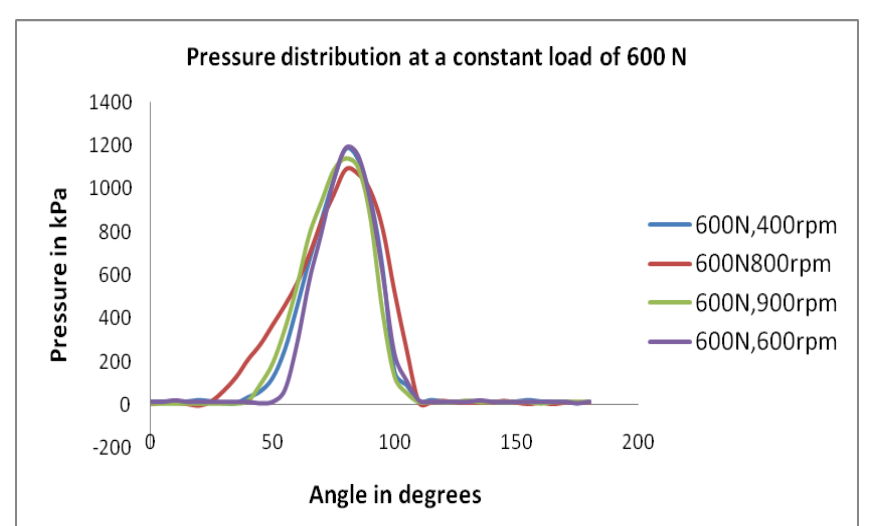

Fig. 22 Pressure distribution variation at constant load of $600 \mathrm{~N}$

\subsection{Analytical Method of Viscosity Calculations 4.5.1. Calculation of V iscosity of Used Oil by Red Wood Viscometer for SAE 20 w50 Oil}

Theoretical calculation of pressure using Redwood viscometer for SAE20W50 and SAE90 oils are tabulated as follows:

Table6. Description of Redwood Viscometer test for SAE20W50 oil used in bearing

\begin{tabular}{|c|c|c|c|c|c|}
\hline No & \begin{tabular}{|l} 
Temp. \\
in $^{\circ} \mathrm{C}$
\end{tabular} & $\begin{array}{l}\text { Time in redwood } \\
\text { (R) seconds for the } \\
\text { oil to flow down } \\
\text { from the flask to } \\
50 \mathrm{ml} \text {. beaker }\end{array}$ & $\begin{array}{l}\text { Mass }\left(m_{1}\right) \\
\text { of empty } \\
\text { flask in } \\
\text { gra ms }\end{array}$ & $\begin{array}{l}\text { m}_{2} \text { (gms) } \\
=\text { mass of } \\
\text { empty } \\
\text { flask + } \\
50 \mathrm{ml} \text { of } \\
\text { lubricant } \\
\text { mass }\end{array}$ & $\begin{array}{l}\text { Kinematic } \\
\text { Viscosity } \\
\text { in } \mathrm{m}^{2} / \mathrm{sec}\end{array}$ \\
\hline 1 & 35 & 610 & 21.02 & 63.16 & $150.5^{*} 1^{-6}$ \\
\hline
\end{tabular}

$V=((0.247 * 610)-(50 / 100)) 10^{-6} \mathrm{~m}^{2} / \mathrm{sec}(100<\mathrm{R}<2000)$

$$
=150.58 * 10^{-6} \mathrm{~m}^{2} / \mathrm{sec}
$$

Actual viscosity of oil [12] at $35^{\circ} \mathrm{C}$ as per data sheet is $171 * 10^{-6} \mathrm{~m}^{2} / \mathrm{sec}$

\subsubsection{Calculation of Viscosity of Tested Oil by Red Wood Viscometer for SAE 90 Oil}

Following calculations and tabulated data are for lubrication oil SAE90.

Table7. Description of Redwood Viscometer test for SAE20W50 oil used in bearing

\begin{tabular}{|c|c|c|c|c|c|}
\hline No & $\begin{array}{l}\text { Temp } \\
\text { in }{ }^{\circ} \mathbf{C}\end{array}$ & $\begin{array}{l}\text { Time in } \\
\text { redwood }(\mathrm{R}) \\
\text { seconds for the } \\
\text { oil to flow down } \\
\text { from the flask to } \\
50 \mathrm{ml} \text {. beaker }\end{array}$ & $\begin{array}{l}\text { Mass } \\
\left(m_{1}\right) \text { of } \\
\text { empty } \\
\text { flask in } \\
\text { grams }\end{array}$ & $\begin{array}{l}\mathrm{m}_{2}(\mathrm{gms})= \\
\text { mass of } \\
\text { empty flask } \\
+50 \mathrm{ml} \text { of } \\
\text { lubricant } \\
\text { Mass }\end{array}$ & $\begin{array}{r}\text { Kinematic } \\
\text { Viscosity } \\
\text { in } \mathrm{m}^{2} / \mathrm{sec}\end{array}$ \\
\hline 1 & 35 & 625 & 21.02 & 63.38 & $162 * 10^{-6}$ \\
\hline
\end{tabular}


$V=\left(\left(0.247^{*} 625\right)-(50 / 100)\right) 10^{-6} \mathrm{~m}^{2} / \mathrm{sec}(100<R<2000)$

$=162 * 10^{-6} \mathrm{~m}^{2} / \mathrm{sec}$

Actual viscosity of oil [12] at $35^{\circ} \mathrm{C}$ as per data sheet is $180^{*} 10^{-6} \mathrm{~m}^{2} / \mathrm{sec}$.

\subsection{Calculations of Performance Characteristics}

Calculation of load carrying capacity and maximum angle of pressure development has been done in the following cases.

\subsubsection{For SAE 20w50 Oil}

For a given maximum pressure $=234 \mathrm{KPa}$ and maximum pressure angle $=167^{\circ}$. From the graph obtained from the hand book [12], for $=1.57$ and $\mathrm{S}=0.03$, we get

Therefore co efficient of friction was $6.9435 *$

The frictional force was found to be $6.9435^{*} 10^{-3}$ $* 52.14 * 10^{3}=362 \mathrm{~N}$

\subsubsection{For SAE90 Grade Oil}

Given maximum pressure $=200 \mathrm{KPa}$ and maximum pressure angle: $154^{\circ}$.From the graph obtained from the hand book (graph 24-18 page 24-24) for $=1.57$ and $\mathrm{S}=0.03$ we get, Therefore co efficient of friction is 6.9435 . The frictional force is $6.9435^{*} 10^{-3}$ $* 56.3 * 10^{3}=390.91 \mathrm{~N}$.

\section{CONCLUSIONS}

The following conclusions are drawn from the experimental study carried out:

1. Variation of pressure distribution with respect to angle of rotation (degrees) for both SAE20w50 and SAE 90 oils revealed a pressure increases from 0 to $80^{0}$ of rotation and then decreases for the remaining rotation of bearing. This clearly indicates the presence of a hydrodynamic lubrication which is the need of high speed journal bearing.

2. The maximum value of pressure was found to be $1440.8 \mathrm{KPa}$ and be $1185.8 \mathrm{KPa}$ for both the oils respectively. This variation is due to the rotational speed and the viscous nature of an oil and viscous nature of the oil, change of eccentricity etc. but shown good performance under various loading and speed.

2. It is noticed that, there is a decrease in viscosity by $10-11 \%$ for SAE20W50 oil and SAE90 oil which shows viscosity has no or little temperature effect and life of the bearing increases

4. It is also seen, there is a maximum stress of $10.487 \mathrm{MPa}$, maximum strain of $6.06 \times 10^{-5}$ and maximum deformation of $0.0015 \mathrm{~mm}$ at the journal bearing interface. Due to their small values, strength and life of the bearing will be higher.

5. In order to verify pressure distribution, CFD analysis can be carried in next stage.

\section{REFERENCES}

1. J. Boyd and B. P. Robertson, Tribology International, vol. 194 (8), 2009, pp. 378390.

2. Majumd har .B.C, Introduction To Tribology of Bearing, Wheeler Publishing, New Delhi 2001.

3. Baskar S and Sriram G Experimental analysis of hydrodynamic journal bearing under different bio lubricants. 2012, pp.132135.

4. Mane RM, Soni S. Analysis of Hydrodynamic Plain Journal Bearing, Proc. 2013 COMSOL Conference, Bangalore, 2013.

5. Gao G, Yin Z, Jiang D, Zhang X. Numerical analysis of plain journal bearing under hydrodynamic lubrication by water, Tribology International, Elsevier, vol. 75, 2014, pp. 31-38.

6. Chauhan A, Singla A, Panwar N, Jindal P. CFD Based Thermo-Hydrodynamic Analysis of Circular Journal Bearing, Vol. 4(5), 2014, pp.475-482.

7. Dhande D, Pande DW, Chatarkar V. Analysis of Hydrodynamic Journal Bearing 
Using Fluid Structure Interaction Approach, vol. 4, August 2013, pp.3389-3392.

8. Aher Mahesh, Belkar Sanjay, Kharde R.R. Pressure Distribution Analysis of Plain Journal Bearing with Lobe Journal Bearing, IJERT, 2013.

9. Gulab, Wakchaure, Keshav and Dwarapalli Ravi Kumar, Comparative Study of Different Analytical Method to Reynolds Equation with Experimental Method to loacate Maximum Pressure of Journal Bearing, 2014.

10. Guo Z, Hirano T, Kirk RG. Application of CFD Analysis for Rotating Machinery-Part I: Hydrodynamic, Hydrostatic Bearings and Squeeze Film Damper. J Eng Gas Turbines Power, vol. 127 (2), 2005, pp. 445.

11. Nuruzzaman D.M., Khalil M.K., Chowdhury M.A., Rahaman M.L., Study on Pressure Distribution and Load Capacity of a Journal Bearing Using Finite Element Method and Analytical Method, vol.5, 2010, pp.1-8.

12. K.Lingaiah. Machine Design, vol.2, McGraw hill publication, second edition 2001.

13. J. Sun, G. Changlin, "Hydrodynamic lubrication analysis of journal bearing considering misalignment caused by shaft deformation," Tribology International, vol. 37, 2004, pp. 841-848.

14. K. Zhang, "Effects of test conditions on the tribological behavior of a journal bearing in molten zinc, Wear, vol. 259, 2005, pp. 12481253.

15. Fredrick T. Schuller, Experiments on the Stability of water lubricated three lobe hydrodynamic bearing, NASA TND, vol. 6315, pp.1-35.

16. Rakesh Sehgal, "Experimental Measurement of oil film temperature of Elliptical Journal Bearing profile using different grade oil", Tribology online, April 2010, pp. 291-299.

17. Pinkus, O., and Sternlicht, B., 1961, Theory of Hydrodynamic Lubrication, McGrawHill, New York.

18. Cabrera DL, Woolley NH, Allanson DR, Tridimas YD. Film pressure distribution in water-lubricated rubber journal bearings. Proc. Inst Mech. Eng, Part J:J Eng. Tribology, vol. 219, 2005, pp.125-32.

19. De Kraker Alex, van Ostayen Ron AJ, Rixen Daniel J. Calculation of Stribeck curves for(water) lubricated journal bearings. Tribology International, vol.40, 2007, pp.459-69.

20. D'Agostino V, Senatore A. Analytical solution for two-dimensional Reynolds equation for porous journal bearings. Industrial Lubricant Tribology, vol.58, 2006, pp.110-117.

21. J. Ferron, J. Frene, R. Boncompain,A Study of theThermo-hydrodynamic Performance of a Plain Journal BearingComparison Between The ory and Experiments", Transactions of the ASME, Vol. 105, July 1983, pp.422-428.

22. D.T. Gethin, Thermo Hydrodynamic Behaviour of HighSpeed Journal Bearings, Tribology International, vol. 29(7), 1996, pp. 579-596. 